\title{
Epidemiological and Serological Study of Leishmaniasis in Najran Region, Saudi Arabia
}

\author{
Mokhtar I. Khalil \\ Department of Applied Medical Sciences, Community College, Najran University, \\ Najran, Saudi. Arabia. \\ Community College, Najran University, Najran, Saudi Arabia. \\ Tel: 966-502-362-042Ｅ-mail: mokhtar179@yahoo.com
}

\begin{abstract}
Mosa M. Bahnass
Department of Applied Medical Sciences, Community College, Najran University, Najran, Saudi Arabia. Department of Animal Medicine (Infectious Diseases), Faculty of Veterinary Medicine, Zagazig University, Egypt.

Community College, Najran University, Najran, Saudi Arabia.

Tel: 966-550-196-077Ｅ-mail: abuahmedm2000@gmail.com

M. I. M Abdallah

Department of Applied Medical Sciences, Community College, Najran University, Najran, Saudi. Arabia.

Community College, Najran University, Najran, Saudi Arabia.

Tel: 966-559-121-656_E-mail: meab312@yahoo.com
\end{abstract}

Received: December 27, 2016 Accepted: January 31, 2017 Published: February 21, 2017

doi:10.5296/jbls.v8i1.10793 URL: https://doi.org/10.5296/jbls.v8i1.10793

\begin{abstract}
Leishmaniasis is a public health and veterinary hazard. Screening of serum samples of 384 human and 387 domestic animals were carried out by indirect hemagglutination assay (IHAT) to detect antibodies against $L$. donovani and to see the involvement of animal reservoirs in Najran region, Saudi Arabia. The overall prevalence of human Leishmaniasis infection in Najran area, Saudi Arabia was $8.3 \%$. The prevalence rate of human Leishmaniasis was
\end{abstract}


significantly higher in summer $(21.9 \%)$ and spring $(8.3 \%)$ than in winter and autumn. In addition, the prevalence rate of human Leishmaniasis was significantly higher in old age $(17.6 \%)$ and young period (7.3\%). Out of 53 females and 331 males, $3(5.7 \%)$ females and 29 $(8.8 \%)$ males were found to be infected with human Leishmaniasis, respectively. The highest titer in human was $1 / 256$ with percentage of $43.8 \%$. Antibody against L. donovani in domestic animals was detected and the overall proportion of occurrence was $1.6 \%$. The prevalence rate of Leishmaniasis infection was significantly higher in goats than in sheep, camel and horses. The highest titer (1/512) was in goats. The study was thrown light on infected African and Asian workers as source of Leishmaniasis infection. Also, this study suggests the possibility of varied species of domestic animals to harbor the parasite and hence play a central role in the transmission. Consequently, this may hurdle our clarification of disease epidemiology.

Keywords: Leishmaniasis, Leishmania, Sandfly, Epidemiology, Human, Animals, Serology, Najran, Saudi Arabia

\section{Introduction}

Leishmaniasis are zoonotic worldwide spectrum, vector-borne communicable parasitic diseases and of public health concern for many countries around the world (Dantas-Torres, 2006). Natural reservoir hosts include man (anthroponotic cycle) (human-sandfly-human) and dogs or wild animals (zoonotic cycle). L. donovani is anthroponotic; it is mainly transmitted between people, who act as the reservoir hosts (Roberts et al., 2000). Anthroponotic visceral leishmaniasis, caused by L. donovani, occurs mainly in Sudan and Somalia, however, zoonotic visceral leishmaniasis, caused by L. infantum, occurs in most countries of the region (Postigo, 2010). Climate and other environmental changes have the potential to expand the geographic range of the sand fly vectors and the areas in the world where leishmaniasis is found (Elnaiem et al., 2003). Very little is known about identification of visceral Leishmanisis in Saudi Arabia but there was many studies in cutaneous Leishmanisis (Bienzle et al., 1978; Al-Zahrani et al., 1979; Buttiker et al., 1982; Peters et al., 1985; Peters and Al-Zahrani, 1987; Dye et al., 1989; Al-Zahrani et al., 1989, Morsy et al., 1991; Al-Shammari et al., 1992; Al- Tawfiq and Abukhamsin, 2004). In Makkah, Saudi Arabia, Leishmania isolates were characterized from Makkah Al-mukarramah specialized hospital (Morsy et al., 1993). The studied isolates were two L. donovani zymodeme LON-41 (VL Indian patient) and LON-46 (VL Sudanese patient), three L. tropica zymodeme LON-71 (2 CL Yemenis patients) and LON-22 (CL Egyptian patient) and two L. major zymodeme LON-4 (2 CL Saudi patients). Several reports concerning with the isolation of L. tropica from P. sergenti sandfly in Middle-Eastern countries (Al-Zahrani et al., 1988 and Pazarbasi et al., 2006). Also, isolation of L. major from P. papatasi sandfly was reported (Abou El-Ela et al., 1995 and Oshaghi et al., 2010). Serologically, high antibody levels are observed prior to detection of parasite specific $\mathrm{T}$ cell responses (Ghose et al., 1980). Most widely used serological techniques of Leishmaniasis are indirect immunofluorescent antibody test (IFAT) (Mancianti \& Meciani, 1988), direct agglutination test (DAT) (Harith et al., 1988), enzyme-linked immunosorbent assay (ELISA) (Amin et al., 1985 and Zijlstra et al., 1998), dot-ELISA (Fisa et al., 1997), latex agglutination test (Lockwood \& Sundar, 2006). The 


\section{Macrothink}

purpose of the present study was to detect the prevalence of Leishmaniasis in Najran region, Saudi Arabia and control of it by knowing the reservoir of the disease.

\section{Methods}

\subsection{Geographic Area of Research Study}

Najran is a city in southwestern Saudi Arabia near the border with Yemen. It is the capital of Najran Province. Najran enjoys three different geographic landscapes, and they are the oases, mountains, and desert at its eastside. The average temperature in Najran ranges from 14.6 to 30.9. The average annual rainfall is $83-\mathrm{mm}$. (figure 1 ).

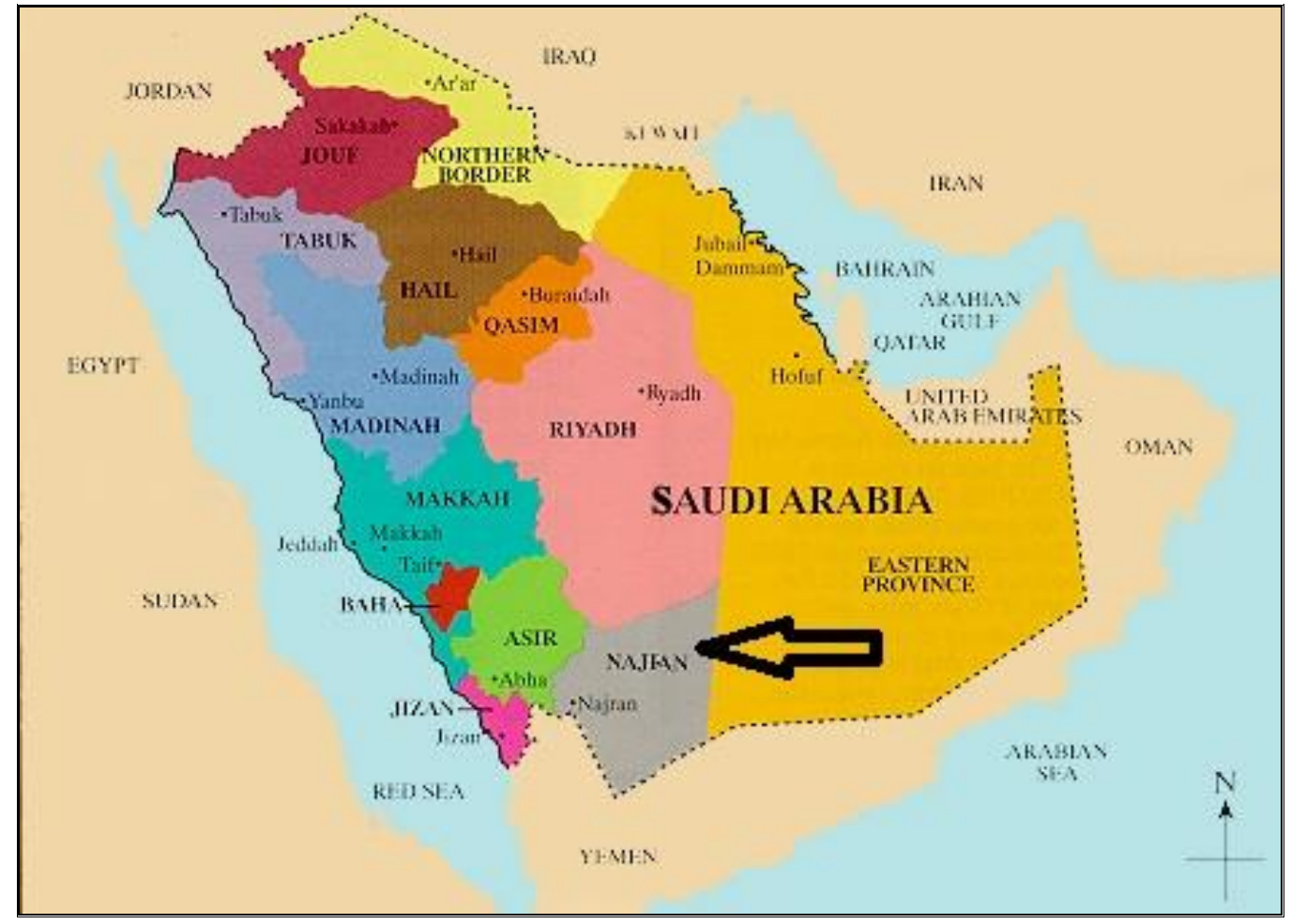

Figure 1. Map of Saudi Arabia showing the geographic location of Najran (arrow), region of Saudi Arabia, located in the south of the country along the border with Yemen.

\subsection{Ethical Consideration}

The University Ethical Board gave permission to conduct the study within the institutional research mandate as stipulated by the National Ethical Board.

\subsection{Collection of Human Serum Samples}

384 human serum samples were obtained from the different nationality people of both genders and different ages, and from different parts and environmental seasons in Najran. The samples will be obtained from apparently healthy human to make serological survey (Table $1)$. 
Table 1. Different nationality people in Najran region, Saudi Arabia.

\begin{tabular}{|c|c|c|c|c|c|c|c|c|c|c|}
\hline \multirow[t]{2}{*}{ Nationality } & \multicolumn{4}{|c|}{ Season* } & \multicolumn{3}{|c|}{ Age** $^{* *}$} & \multicolumn{2}{|c|}{ Sex } & \multirow[t]{2}{*}{ total } \\
\hline & 1 & 2 & 3 & 4 & A & B & $\mathrm{C}$ & $q$ & $\hat{0}$ & \\
\hline Indian & 38 & 18 & 31 & 34 & 0 & 97 & 24 & 8 & 113 & 121 \\
\hline Saudi Arabian & 4 & 25 & 9 & 11 & 14 & 33 & 2 & 5 & 44 & 49 \\
\hline Kenyan & 5 & 0 & 0 & 0 & 0 & 5 & 0 & 0 & 5 & 5 \\
\hline Filipino & 7 & 0 & 9 & 7 & 0 & 22 & 1 & 2 & 21 & 23 \\
\hline Egyptian & 11 & 19 & 9 & 16 & 2 & 47 & 6 & 11 & 44 & 55 \\
\hline Yemeni & 8 & 10 & 14 & 3 & 0 & 30 & 5 & 10 & 25 & 35 \\
\hline Sudanese & 12 & 13 & 10 & 12 & 0 & 41 & 6 & 13 & 34 & 47 \\
\hline Ethiopian & 8 & 3 & 4 & 5 & 0 & 17 & 3 & 3 & 17 & 20 \\
\hline Sri Lankan & 2 & 0 & 0 & 3 & 0 & 5 & 0 & 0 & 5 & 5 \\
\hline Jordanian & 1 & 0 & 0 & 0 & 0 & 1 & 0 & 0 & 1 & 1 \\
\hline Moroccan & 0 & 0 & 1 & 1 & 0 & 2 & 0 & 0 & 2 & 2 \\
\hline Neapolitan & 0 & 0 & 5 & 0 & 0 & 3 & 2 & 1 & 4 & 5 \\
\hline Pakistani & 0 & 0 & 0 & 4 & 0 & 4 & 0 & 0 & 4 & 4 \\
\hline Bangladeshi & 0 & 8 & 4 & 0 & 0 & 10 & 2 & 0 & 12 & 12 \\
\hline Total & 96 & 96 & 96 & 96 & 16 & 317 & 51 & 53 & 331 & 384 \\
\hline
\end{tabular}

* Season: (1) summer, (2) autumn, (3) winter and (4) spring.** age: (A) between 1 year and 19 year, (B) between 20 year and 39 year and (C) between 40 year and 59 year.

\subsection{Collection of Animal Serum Samples}

387 animal serum samples (116 goat, 104 sheep, 140 camel and 27 horse) were collected from different farm localities in Najran to detecting the reservoir and the site of high infection. Human and animal blood samples were collected and transported to the Department of Applied Medical Sciences Lab, Community College, Najran University. All sera were kept in deep freeze at $-20^{\circ} \mathrm{C}$ until used for serological diagnosis.

\subsection{Serological Test}

The collected sera were examined for detection of specific antibodies to Leishmania donovani using the indirect hemagglutination assay (IHAT) with a commercially available kit (Cellognost Leishman, Siemens Healthcare Diagnostic Products GmbH, 35041 Marburg/Germany) according to the manufacturer's instructions. Serum dilution of 1:32 and higher provide diagnostically useful titers. Mid-range serum titers lie between 1:256 and 1:2048. Positive and negative controls were included in each test (Sundar and Rai, 2002).

\subsection{Statistical Analysis}

The data were analyzed According to The t-test and one-way Analysis of Variance (ANOVA) analysis. Differences were considered significant when $\mathrm{P} \leq 0.05$.

\section{Results}

The overall prevalence of human Leishmaniasis infection in Najran area, Saudi Arabia was 
$8.3 \%$ (Table 2). The prevalence rate of human Leishmaniasis was significantly higher $(\mathrm{P}<0.05)$ in summer $(21.9 \%)(21 / 96)$ and spring $(8.3 \%)(8 / 96)$ than in winter and autumn (Table 3). In addition, the prevalence rate of human Leishmaniasis was significantly higher in old age (17.6\%) and young period (7.3\%) (Table 3). Out of 53 females and 331 males, 3 (5.7\%) females and $29(8.8 \%)$ males were found to be infected with human Leishmaniasis, respectively. Human Leishmaniasis infection titers were 1/32, 1/64, 1/256 and 1/512 with percentage of $12.5 \%, 25 \%, 43.8 \%$ and $18.8 \%$, respectively, (Table 3 ). The prevalence rate of human Leishmaniasis was significantly higher $(\mathrm{P}<0.05)$ in Kenyan $(40 \%)$, Sri Lankan $(40 \%)$, Ethiopian (25\%), Bangladeshi (16.7\%) and Sudanese (10.6\%). The infection in Indian, Saudi Arabian, Filipino, Egyptian and Yemeni was 4.9\%, 6.1\%, 4.3\%, 7.3\% and 5.7\%, respectively (Table 3 and figure 2,3,4,5).

There was no infection in Jordanian, Moroccan, Neapolitan and Pakistani (Table 3). The highest titer in human was $1 / 256$ with percentage of $43.8 \%$. According to The t-test and one-way Analysis of Variance (ANOVA) analysis, there was no statistically significant differences in Leishmaniasis seroprevalence in relation to human nationality and the sex (p-value>0.05). There was statistically significant differences in Leishmaniasis seroprevalence in relation to season variation and the age ( $p$-value $<0.05)$, but confidence intervals are usually expressed with $95 \%$ confidence. Prevalence of animals Leishmaniasis infection in Najran area, Saudi Arabia in sheep, goats, camels and horses was $0.96 \%, 4.3 \%$, $0 \%$ and $0 \%$, respectively (Table 4 and Figure 6 ). The prevalence rate of Leishmaniasis infection was significantly higher $(\mathrm{P}<0.05)$ in goats than in sheep, camel and horses. The overall prevalence in animals Leishmaniasis infection in Najran area, Saudi Arabia was $1.6 \%$ ( 6 out of 387). The titer $1 / 512$ was significantly highest $(\mathrm{P}<0.05)$ in goats.

Table 2. Seroprevalence of Leishmaniasis infection in human in relation to Nationality

\begin{tabular}{|l|c|c|c|}
\hline $\begin{array}{c}\text { Human } \\
\text { Nationality }\end{array}$ & $\begin{array}{c}\text { Examined } \\
\text { Numbers }\end{array}$ & $\begin{array}{c}\text { Number of } \\
\text { positive }\end{array}$ & $\begin{array}{c}\text { Percentage of } \\
\text { positive (\%) }\end{array}$ \\
\hline Indian & 121 & 6 & 4.9 \\
\hline Saudi Arabian & 49 & 3 & 6.1 \\
\hline Kenyan & 5 & 2 & 40 \\
\hline Filipino & 23 & 1 & 4.3 \\
\hline Egyptian & 55 & 4 & 7.3 \\
\hline Yemeni & 35 & 2 & 5.7 \\
\hline Sudanese & 47 & 5 & 10.6 \\
\hline Ethiopian & 20 & 5 & 25 \\
\hline Sri Lankan & 5 & 2 & 40 \\
\hline Jordanian & 1 & 0 & 0 \\
\hline Moroccan & 2 & 0 & 0 \\
\hline Neapolitan & 5 & 0 & 0 \\
\hline Pakistani & 4 & 0 & 0 \\
\hline Bangladeshi & 12 & 2 & 8.3 \\
\hline Total & 384 & 32 & \\
\hline
\end{tabular}




\section{Macrothink}

Table 3. Seroprevalence of Leishmaniasis infection in human in relation to season, age and sex.

\begin{tabular}{|c|c|c|c|c|c|c|c|c|c|c|c|c|c|}
\hline \multirow[t]{2}{*}{ Nationality } & \multicolumn{4}{|c|}{ Season* } & \multicolumn{3}{|c|}{$\mathrm{Age}^{* *}$} & \multicolumn{2}{|c|}{ sex } & \multicolumn{4}{|c|}{ Titer*** } \\
\hline & 1 & 2 & 3 & 4 & $\mathrm{~A}$ & $\mathrm{~B}$ & $\mathrm{C}$ & q & 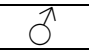 & I & II & III & IV \\
\hline Examined Numbers & 96 & 96 & 96 & 96 & 16 & 317 & 51 & 53 & 331 & & & & \\
\hline Number of positive & 21 & 1 & 2 & 8 & 0 & 23 & 9 & 3 & 29 & 4 & 8 & 14 & 6 \\
\hline Positive (\%) & 21.9 & 1.04 & 2.08 & 8.3 & 0 & 7.3 & 17.6 & 5.7 & 8.8 & 12.5 & 25 & 43.8 & 18.8 \\
\hline
\end{tabular}

* Season: (1) summer, (2) autumn, (3) winter and (4) spring.

** Age: (A) childhood, (B) young period and (C) old age.

***Titer: (I) $1 / 32$, (II) $1 / 64$, (III) $1 / 256$ and (IV) $1 / 512$.

Table 4. Seroprevalence of Leishmaniasis infection in farm animals.

\begin{tabular}{|c|c|c|c|c|c|c|c|c|c|c|c|c|c|}
\hline \multirow{3}{*}{ Species } & \multirow{3}{*}{ Examined } & \multirow{3}{*}{ Positive } & \multirow{3}{*}{ Positive (\%) } & \multicolumn{10}{|c|}{ Titer } \\
\hline & & & & \multicolumn{2}{|c|}{$1 / 32$} & \multicolumn{2}{|c|}{$1 / 64$} & \multicolumn{2}{|c|}{$1 / 128$} & \multicolumn{2}{|c|}{$1 / 256$} & \multicolumn{2}{|c|}{$1 / 512$} \\
\hline & & & & $\mathrm{N}$ & $\%$ & $\mathrm{~N}$ & $\%$ & $\mathrm{~N}$ & $\%$ & $\mathrm{~N}$ & $\%$ & $\mathrm{~N}$ & $\%$ \\
\hline Sheep & 104 & 1 & 0.96 & 1 & 100 & 0 & 0 & 0 & 0 & 0 & 0 & 0 & 0 \\
\hline Goats & 116 & 5 & 4.3 & 1 & 20 & 1 & 20 & 2 & 40 & 0 & 0 & 1 & 20 \\
\hline Camels & 140 & 0 & 0 & 0 & 0 & 0 & 0 & 0 & 0 & 0 & 0 & 0 & 0 \\
\hline Horse & 27 & 0 & 0 & 0 & 0 & 0 & 0 & 0 & 0 & 0 & 0 & 0 & 0 \\
\hline Total & 387 & 6 & 1.6 & 2 & 33.3 & 1 & 16.7 & 2 & 33.3 & 0 & 0 & 1 & 16.7 \\
\hline
\end{tabular}

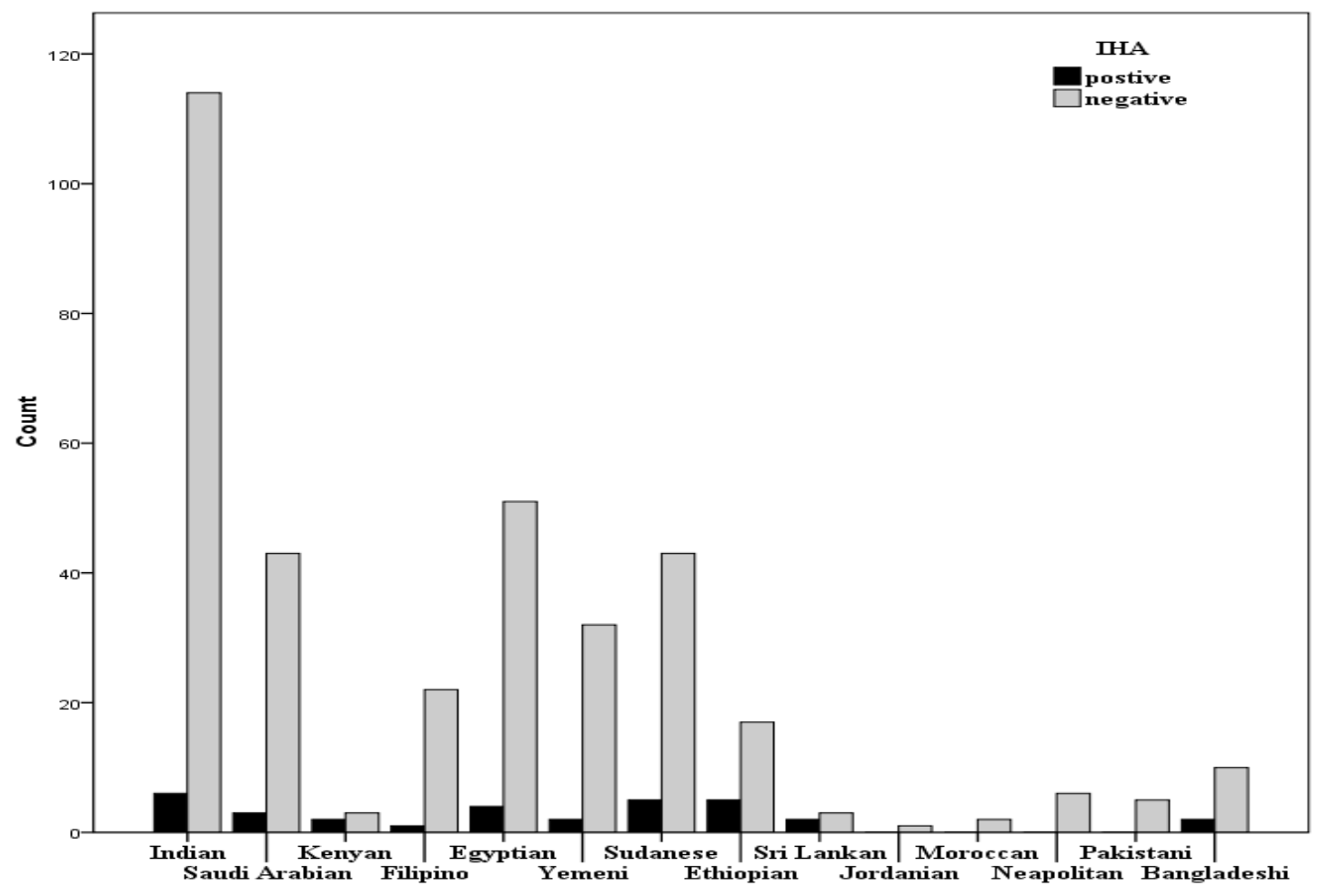

Figure 2. Seroprevalence of Leishmaniasis infection in human in relation to Nationality. 


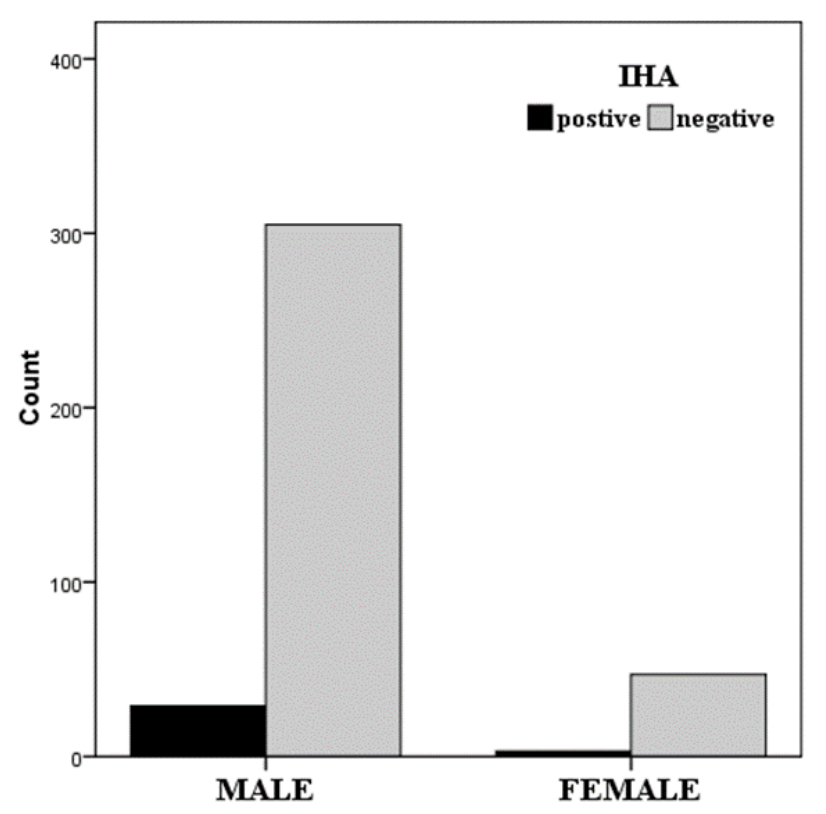

Figure 3. Seroprevalence of Leishmaniasis infection in human in relation to sex.

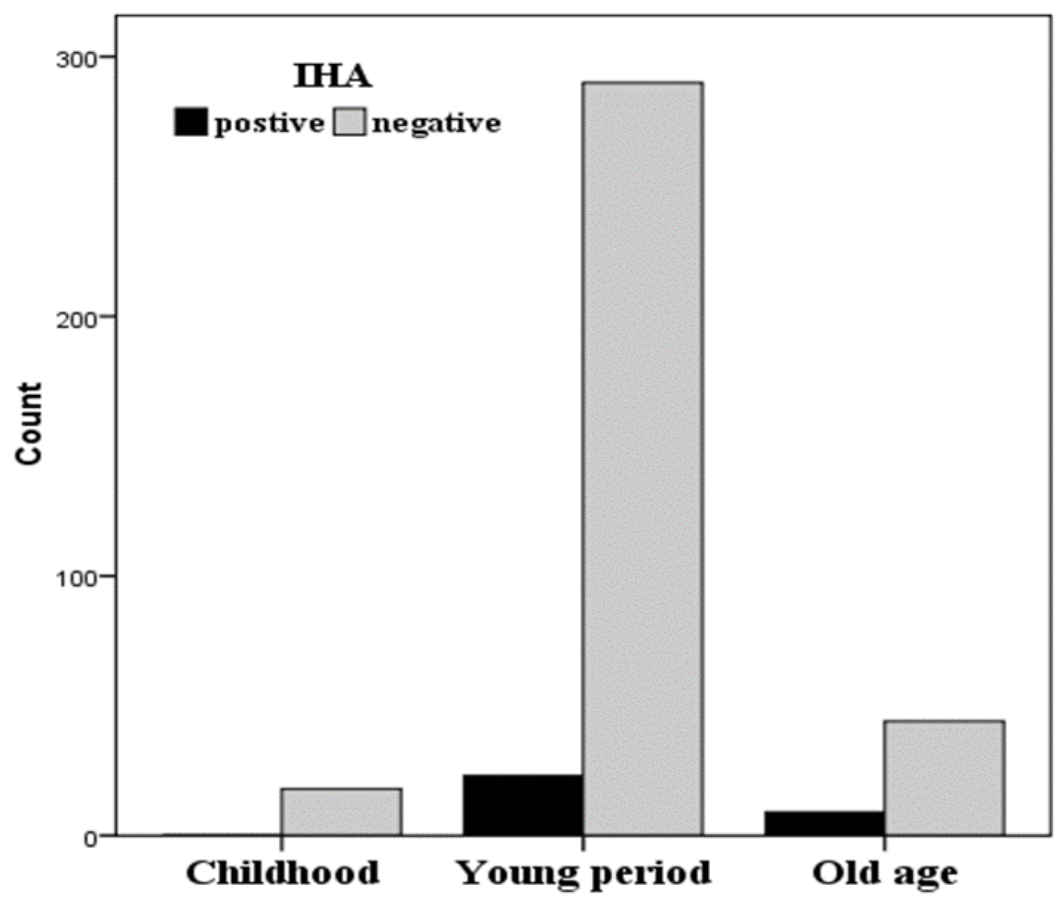

Figure 4. Seroprevalence of Leishmaniasis infection in human in relation to age. 


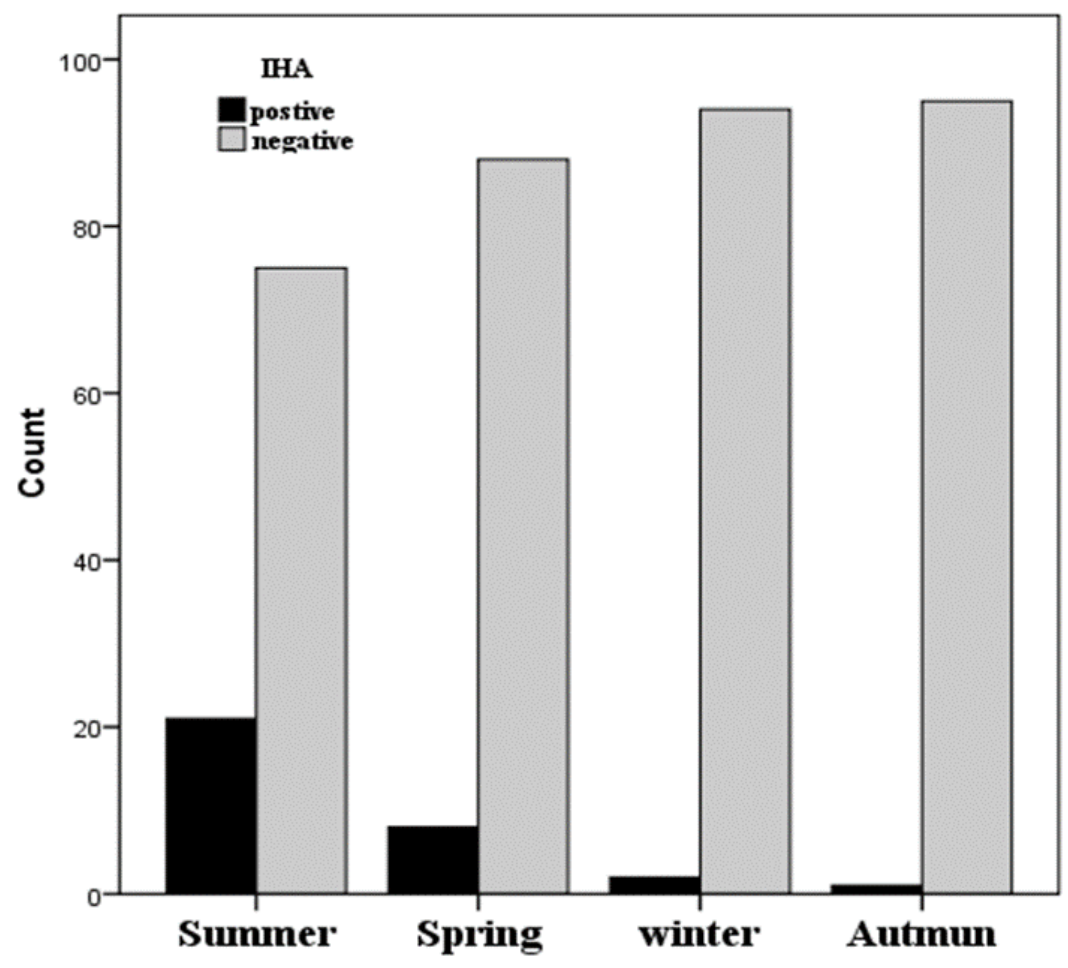

Figure 5. Seroprevalence of Leishmaniasis infection in human in relation to season.

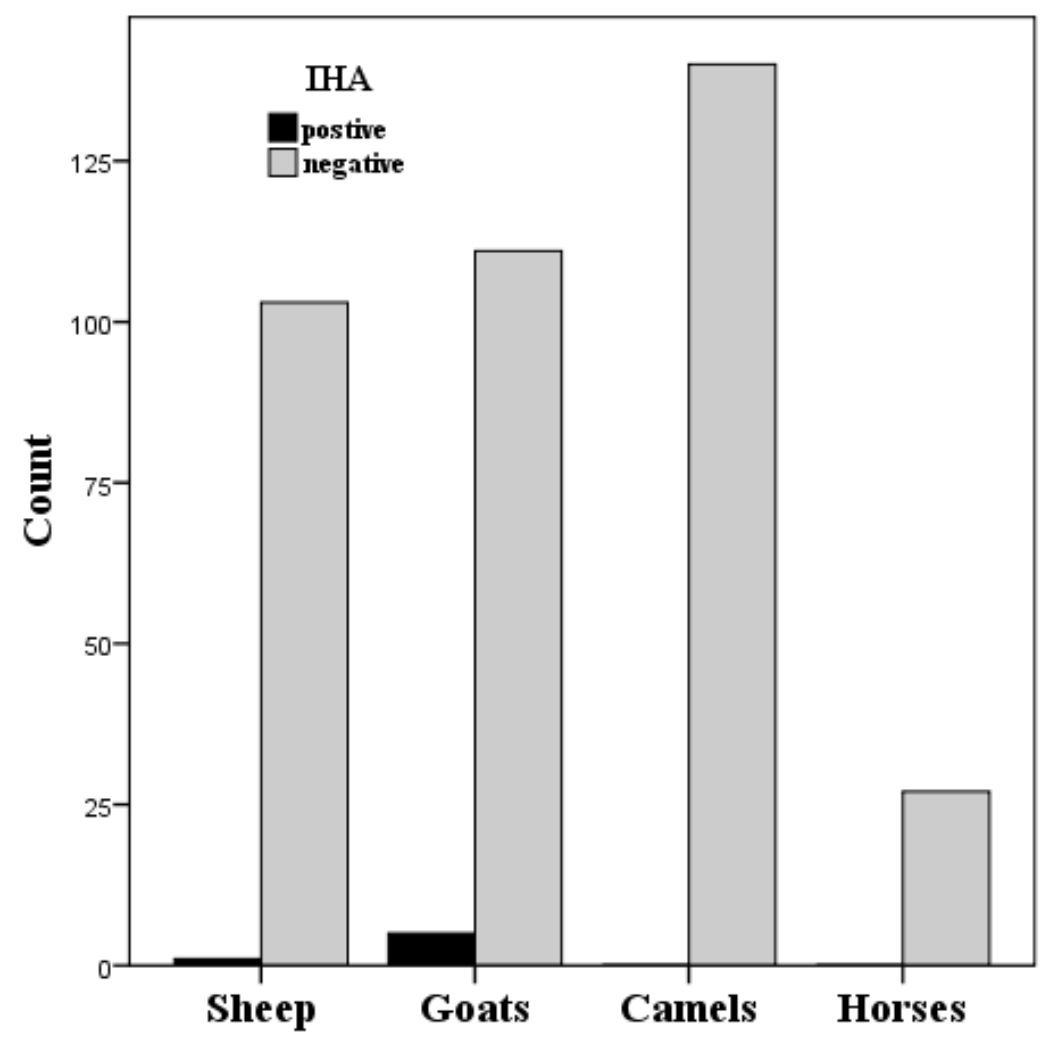

Figure 6. Seroprevalence of Leishmaniasis infection in farm animals. 


\section{Discussion}

From the epidemic point of view, Leishmaniasis is the third-major vector-born disease killer in the world after malaria and sleeping sickness (Bern et. al., 2008). It is estimated about 500,000 infections each year worldwide (Desjeux, 2001).

The data in corresponding to our study show that all age groups are susceptible to infection with Leishmania (Kubba, 1987). Seasonal pattern of the disease correlates with the known activity of the vector (Buttiker \& Lewis, 1979 and Al-Cindan et al., 1984). In our study in Najran, southern region in Saudi Arabia, L. donovani Sero-postive persons (8.3\%) was recorded, Similar study in Gizan province, south-west Saudi Arabia by Ibrahim et al. (1992) in which L. donovani s.1. LON42 was isolated from human visceral Leishmaniasis patients living in this area. The disease peaks in late spring and summer, then declines sharply in winter. This is similar to the variation seen in the Mediterranean variety (Al-Orainey et al., 1994). We found Leishmania serologically positive in domestic animals (sheep and goats) from Najran area, Saudi Arabia, mostly in goats (4.3\%). Similar conclusion was detected by Bhattarai et al. (2010) from Dharan-17, where infection was mostly in goats (16\%). Even if our results indicate that goats might be involved in the epidemiology of Visceral Leishmaniasis, they do not necessarily mean that these animals constitute a reservoir host for L. donovani. Criteria for the definition of Leishmania reservoir hosts were recently reviewed by Chaves et al. (2007) and include sand fly foraging behaviour and feeding preferences and the dynamics of infections in assumed reservoir hosts; a key question is the clearance times (chronicity) of infections. Whether the phenomenon observed here can be extrapolated to other VL-endemic foci should also be explored.

Najran area, Saudi Arabia is a new emerging focus, and in the absence of immunity, human and animal populations could be more sensitive to Leishmania infections. Our observations warrant further investigation and a close monitoring of goats and other peridomiciliary animals. If the role of these animals in the transmission cycle is confirmed, the potential implications could affect Visceral Leishmaniasis control programs in the region. Comparison of the results from animals with those from human samples from Najran area, Saudi Arabia provided additional interpretation of the animal results. Leishmania spp. positivity was found to be $\approx 4 \times$ lower among animals than among persons ( $1.6 \%$ vs. $8.3 \%$, respectively). Although these data weren't consistent with data on the feeding behavior of Phlebotomus argentipes blood-sucking flies, reported previously by Palit et al. (2005) those attributed to the most of seropositive persons was in old age. Phlebotomus argentipes blood-sucking flies seems to breed essentially in cattle sheds (Singh et al., 2008) and are 5x more attracted to cattle than to persons (Dinesh et al., 2001) and feed more on animals $(62.80 \%)$ than on persons $(24.92 \%)$, according to a study in India. The occurrences of antibody for L. donovani differ among different animal species in the present and previous studies (Mukhtar et al., 2000). In our study the highest seropositivity of $4.3 \%$ was found in goat while other similar study (Kenubih et al., 2014) in north West Ethiopia found cattle have high seroposetivity $41.9 \%$.

\section{Conclusion}

The study was thrown light on infected African and Asian workers as source of Leishmaniasis 
infection in south area of Najran, Saudi Arabia. Also, this study suggests the possibility of varied species of domestic animals to harbor the parasite and hence play a central role in the transmission. Consequently, this may hurdle our clarification of disease epidemiology. Health education activities are still required to sensitize people living in endemic areas, medical and public health managers, and individuals at risk on leishmaniasis. Also, control measures against sand flies and reservoir hosts need to be further evaluated in terms of their effect on disease incidence.

\section{Acknowledgement}

The authors thank the officials of hospitals, Abattoirs and animal farms in Najran, Saudi Arabia for facilitating the performance of this research.

\section{References}

Abou El-Ela, R. G., Morsy, T. A., Rifaat, M. M., et al. (1995). Morphological studies on Phlebotomus papatasi (Scopoli) in Riyadh city, Saudi Arabia. J Egypt Soc Parasitol, 25, 631-48. PMid:8586859. https://doi.org/10.1111/j.1365-4362.1984.tb04510.x

Al-Cindan, Y., Abdul-Aziz, O., \& Kubba, R. (1984). Cutaneous leishmaniasis in Al-Hassa, Saudi Arabia. Int J Dermatol, 23, 194-197.

https://doi.org/10.1111/j.1365-4362.1984.tb04510.x.

Al-Orainey, I. O., Gasim, I. Y., Singh, L. M., et al. (1994). Visceral leishmaniasis in Gizan, Saudi Arabia. Ann Saudi Med., 14, 396-8. PMid:17586953.

Al-Shammari, S., Khoja, T., \& Fehr, A. (1992). Cutaneous leishmaniasis in Riyadh region: four year study of the epidemiological and clinical features. Int J Dermatol, 31, 365-7. https://doi.org/10.1111/j.1365-4362.1992.tb02720.x

Al-Tawfiq, J. A., \& Abukhamsin, A. (2004). Cutaneous leishmaniasis: a 46-year study of the epidemiology and clinical features in Saudi Arabia (1956-2002). Int J Infect Dis., 8, 244-50. https://doi.org/10.1016/j.ijid.2003.10.006

Al-Zahrani, M. A., Peters, W., Evans, D. A., et al. (1988). Phlebotomus sergenti, a vector of Leishmania tropica in Saudi Arabia. Trans $R$ Soc Trop Med Hyg., 82, 416. https://doi.org/10.1016/0035-9203(88)90142-3.

Al-Zahrani, M. A., Peters, W., Evans, D. A., Smith, V., \& Ching, C. I. (1989). Leishmania infecting man and wild animals in Saudi Arabia. Cutaneous leishmaniasis of man in the south-west. Transaction of the Royal Society of Tropical Medicine and Hygiene, 83, 621-628. https://doi.org/10.1016/0035-9203(89)90376-3.

Al-Zahrani, M. A., Peters, W., \& Evans, D. E. (1979). Leishmania infecting man and wild animals in Saudi Arabia: Cutaneous leishmaniasis of man in the south-west. Transaction of the Royal Society of Tropical Medicine and Hygiene, 83, 503-510. https://doi.org/10.1016/0035-9203(89)90267-8

Amin, E. R., Wright, P. A., Kager, P. A., et al. (1985). ELISA using intact promastigotes for 
immunodiagnosis of kala-azar. Trans $R$ Soc Trop Med Hyg., 79, 344-50. https://doi.org/10.1016/0035-9203(85)90376-1.

Bern, C., Maguire, J. H., \& Alvar, J. (2008). Complexities of assessing the disease burden attributable to leishmaniasis. PLoS Negl Trop Dis., 2, 313. https://doi.org/10.1371/journal.pntd.0000313

Bhattarai, N. R., Van der Auwera, G., Rijal, S., et al. (2010). Domestic Animals and Epidemiology of Visceral Leishmaniasis, Nepal. Emerging Infectious Diseases, 16, 231-7. https://doi.org/10.3201/eid1602.090623

Bienzle, U., Ebert, F., \& Dietrich, M. (1978). Cutaneous leishmaniasis in Eastern Saudi Arabia. Epidemiological and clinical features in a nonimmune population living in an endemic area. Transaction of the Royal Society of Tropical Medicine and Hygiene, 29, 188-193. PMid: 675842

Buttiker, W, \& Lewis, D. J. (1979). Ecological studies at Hofuf, Eastern Saudi Arabia, in relation to dermal leishmaniasis. Tropenmed Parasitol, 30, 220-9. PMid:483384

Buttiker, W., Al-Ayed, I. H., \& Al-Rabil, A. H. (1982). Medical and applied zoology in Saudi Arabia. A preliminary study on leishmaniasis in two areas of the Asir Region. Fauna Saudi Arabia, 4, 509-519.

Chaves, L. F., Hernandez, M. J., Dobson, A. P., et al. (2007). Revisiting the criteria for identifying reservoirs for American cutaneous leishmaniasis. Trends Parasitol, 23, 311-6. https://doi.org/10.1016/j.pt.2007.05.003 . PMid:17524806

Dantas-Torres, F. (2006). Leishmune vaccine: the newest tool for prevention and control of canine visceral leishmaniosis and its potential as a transmission-blocking vaccine. Vet Parasitol, 141, 1-8. https://doi.org/10.1016/j.vetpar.2006.05.001 .PMid:16750885

Desjeux, P. (2001). The increase of risk factors for leishmaniasis worldwide. Trans $R$ Soc Trop Med Hyg., 95, 239-43. https://doi.org/10.1016/S0035-9203(01)90223-8

Dinesh, D. S., Ranjan, A., Palit, A., et al. (2001). Seasonal and nocturnal landing/biting behaviour of Phlebotomus argentipes (Diptera:Psychodidae). Ann Trop Med Parasitol, 95, 197-202. https://doi.org/10.1080/00034983.2001.11813629.

Dye, C., Killick-Kendrick, R., Ben Ismail, R., \& Al-Gindany, M. (1989). Zoonotic cutaneous leishmaniasis in Saudi Arabia: results of a preliminary epidemiological survey in Al-Hasa Oasis. Transaction of the Royal Society of Tropical Medicine and Hygiene, 83, 493-498. https://doi.org/10.1016/0035-9203(89)90265-4

Elnaiem, D. A., Schorscher, J., Bendall, A., et al. (2003). Risk mapping of visceral leishmaniasis: the role of local variation in rainfall and altitude on the presence and incidence of kala-azar in eastern Sudan. Am J Trop Med Hyg., 68, 10-17. PMid:12556141

Fisa, R., Gallego, M., Riera, M. C., et al. (1997). Serologic diagnosis of canine leishmaniasis by dot-ELISA. J Vet Diagn Investig, 9, 50-5. https://doi.org/10.1177/104063879700900109. 
PMid:9087925

Ghose, A. C., Haldar, J. P., Pal, S. C., et al. (1980). Serological investigations on Indian kala-azar. Clin Exp Immunol, 40, 318-26. PMid:7438541 PMCid:PMC1536996

Harith, A. E., Kolk, A. H. J., Leeuwenburg, J., et al. (1988). Improvement of a direct agglutination test for field studies of visceral leishmaniasis. J Clin Microbiol, 26, 1321-25.

Ibrahim, E. A., Al-Zahrani, M. A., Al-Tuwaigri, A. S. et al. (1992). Leishmania infecting man and wild animals in Saudi Arabia. The black rat (Rattus rattus) a probable reservoir of visceral leishmaniasis in Gizan province, south-west Saudi Arabia. Transactions of the Royal Society of Tropical Medicine and Hygiene, 86, 513-14.

https://doi.org/10.1016/0035-9203(92)90090-Y

Kenubih, A., Dagnachew, S., Almaw, G., et al. (2015). A preliminary survey of domestic animal visceral leishmaniasis and risk factors in North West Ethiopia. Trop Med Int Health, 20(2), 205-10. https://doi.org/10.1111/tmi.12418. Epub 2014 Nov 20. PMID: 25327874.

Kubba, R., Al-Gindan, Y., el-Hassan, A. M. et al. (1987). Clinical diagnosis of cutaneous leishmaniasis (oriental sore). $J \quad A m$ Acad Dermatol., 16, 1183-9. https://doi.org/10.1016/S0190-9622(87)70155-8

Lockwood, D. N., \& Sundar, S. (2006). Serological tests for visceral leishmaniasis. BMJ, 333, 711-2. https://doi.org/10.1136/bmj.38989.567083.BE. PMid:17023436 PMCid:PMC1592372

Mancianti, F., \& Meciani, N. (1988). Specific serodiagnosis of canine leishmaniasis by indirect immunofluorescence, indirect hemagglutination, and counterimmunoelectrophoresis. Am J Vet Res., 49, 1409-11. PMid:3052194

Morsy, T. A., Sarwat, M. A., Al Shaiby, A. Z., Fawzy, A. F., \& Arafa, M. A. (1993). Isoenzyme characterization of Leishmania isolates from patients in El Nour Specialized Hospital, Saudi Arabia. Journal of Egyptian Society of Parasitology, 23, 871-6. PMid:8308362

Morsy, T. A., Al Gahtani, Y. M., \& Faris, R. M. (1991). Two abnormal cases of anthroponotic cutaneous leishmaniasis in Al Baha, Saudi Arabia. Journal of Egyptian Society of Parasitology, 21, 675-678. PMid:1765678

Mukthar, M. M., Sharif, A. H., El Safi, S. H., et al. (2000). Detection of antibodies of Leishmania donovani in animals in Kala azar endemic regions in eastern Sudan: preliminary report. Trans. R. Soc. Trop. Med. Hyg., 94, 33-6. https://doi.org/10.1016/S0035-9203(00)90429-2

Oshaghi, M., Rasolian, M., Shirzadi, M., et al. (2010). First report on isolation of Leishmania tropica from sandflies of a classical urban Cutaneous leishmaniasis focus in southern Iran. Exp Parasitol, 126, 445-50. https://doi.org/10.1016/j.exppara.2010.05.020. PMid:20570590

Palit, A, Bhattacharya, S. K., \& Kundu, S. N. (2005). Host preference of Phlebotomus argentipes and Phlebotomus papatasi in different biotopes of West Bengal, India. Int $J$ 


\section{Ml Macrothink}

Journal of Biology and Life Science ISSN 2157-6076 2017, Vol. 8, No. 1

Environ Health Res., 15, 449-54. https://doi.org/10.1080/09603120500392525. PMid:16506438

Pazarbasi, A., Alptekin, D., Luleyap, H. U., et al. (2006). Use of enzyme linked immunosorbent assay for detection of natural Leishmania infections in phlebotomine sand flies from southeastern Turkey. $J$ of Med Entomology, 43, 248-51. https://doi.org/10.1603/0022-2585(2006)043[0248:UOEIAF]2.0.CO;2

Peters, W., \& Al-Zahrani, M. A. (1987). The leishmaniases-a public health problem in Saudi Arabia. Saudi Med Journal, 8, 333-343.

Peters, W., El-Bihari, S., \& Liu, C. (1985). Leishmania infecting man and wild animals in Saudi Arabia 1. General survey. Transaction of the Royal Society of Tropical Medicine and Hygiene, 79, 831-839. https://doi.org/10.1016/0035-9203(85)90130-0

Postigo, J. A. (2010). Leishmaniasis in the World Health Organization Eastern Mediterranean Region. Int J Antimicrob Agents, 1, 62-5. https://doi.org/10.1016/j.ijantimicag.2010.06.023

Roberts, L. J., Handman, E., \& Foote, S. J. (2000). Science medicine and the future: Leishmaniasis. BMJ, 321, 801-4. https://doi.org/10.1016/S0277-9536(99)00245-2

Singh, R., Lal, S., \& Saxena, V. K. (2008). Breeding ecology of visceral leishmaniasis vector sand fly in Bihar state of India. Acta Trop, 107, 117-20. https://doi.org/10.1016/j.actatropica.2008.04.025. PMid:18555206

Sundar, S., \& Rai, M. (2002). Laboratory diagnosis of visceral leishmanisis. Clin Diagn Lab Immmunol, 9, 951-8. PMid:12204943 PMCid:PMC120052

Zijlstra, E. E., Daifalla, N. S., Kager, P. A., et al. (1998). rK39 enzyme-linked immunosorbent assay for diagnosis of Leishmania donovani infection. Clin Diagn Lab Immunol, 5, 717-20. PMid:9729541 PMCid:PMC95645.

\section{Copyright Disclaimer}

Copyright for this article is retained by the author(s), with first publication rights granted to the journal.

This is an open-access article distributed under the terms and conditions of the Creative Commons Attribution license (http://creativecommons.org/licenses/by/3.0/). 